\title{
넙다리네갈래근 고강도 운동 시 키네시오 테이평과 러시안 전류의 적용이 근피로도에 미치는 영향
}

\author{
김지원, 김현동, 신민정, 유석호, 이상열, 임예지, 최상아, 손호희" \\ 부산가톨릭대학교 보건과학대학 물리치료학과
}

\begin{abstract}
The Effect of Kinesio Taping and Russian Current on Muscle Fatigue Index of Quadriceps Femoris during High Intensity Exercise

Ji-won Kim, Hyun-dong Kim, Min-jung Shịn, Seok-ho Yoo, Sang-yeol Lee, Ye-ji Lim, Sang-a Choi, Ho-hee Son

Dept. of Physical Therapy, College of Health Sciences, Catholic University of Pusan
\end{abstract}

\begin{abstract}
Purpose The purpose of this study was to investigate the effects of high-intensity exercise with kinesio taping and Russian current stimulation on the fatigue of the quadriceps muscles. Methods 60 healthy adults(male : 18, female : 42) in their twenties in C University located in Busan were participated in this study. Participants randomly allocated into a kinesio taping group ( 20 people), Russian current group ( 20 people), the control group ( 20 people). To induce fatigue in the quadriceps muscle, they performed squat exercises 100 times with kinesio taping, Russian current respectively. The surface EMG was used to measure quadriceps muscle fatigue index. Results After exercise, median frequency was significantly increased on vastus medialis muscle in kinesio taping group $(\mathrm{p}<0.05)$. But, there was no significant difference in other two groups. And, there was no significant difference in median frequency among the groups. Conclusion As a result, when the high intensity exercise was performed with the kinesio taping, there was less muscle fatigue in the vastus medialis muscle. Therefore, the kinesio taping application could affect on muscle fatigue during high-intensity exercise.
\end{abstract}

Key words High intensity exercise, Kinesio taping, Muscle fatigue, Quadriceps, Russian current

Corresponding author Son Hohee (sonhh@cup.ac.kr)

Received date 18 September 2017

Revised date 2 October 2017

Accepted date 19 October 2017

\section{I. 서 론}

반복적이고 고강도의 신체 활동은 피로를 가져오고 이로 인해 근육의 능력을 감소시키고 부상의 위험을 높이거나 관절의 손 상을 가져온다. ${ }^{1)}$ 따라서 효율적인 운동을 위해 근육의 피로를 지연시키거나 운동 후의 빠른 회복을 위해 근력, 지구력 및 유 연성을 증가시키고 준비운동과 마무리 운동을 실시하는 등 여 러가지 노력들이 이루어지고 있다. ${ }^{2)}$ 근피로는 근활성도와 관련 된 근육 수행력의 감소를 뜻하며 근피로가 유발되면 근지구력 과 운동수행력이 감소하며 통증, 부상의 위험을 높이게 된다. ${ }^{3)}$ 따라서 근피로의 예방 및 감소를 위해 흔히 키네시오 테이핑, 맛사지, 전기자극, 스트레칭 등의 방법을 사용하고 있다.

근력을 향상 시키는 보조수단으로 최근에 많이 사용되고 있는 테이핑은 통증을 완화시키는 간편한 방법으로 장애가 있

doi : http:dx.doi.org/10.17817/2017.10.18.111189
는 신체부위가 정상적으로 회복될 수 있도록 도와주는 역할을 한다. ${ }^{4)}$ 또한 관절을 보호하는 효과를 지속시킬 수 있으며, 인 대 염좌 발생 시 테이프 부착으로 인해 순발력과 근지구력과 같은 선수의 운동 수행능력이 감소되지 않는다는 점이 테이핑 의 장점이다. ${ }^{5)}$ 최근에는 테이핑이 근육과 관절을 보호하기 위 한 단순 고정의 개념을 넘어서서 적극적 치료의 한 기법으로 임상이나 스포츠 현장에서 널리 적용되고 있으며, 나아가 근력 과 근 지구력 등의 기능 향상을 목적으로 여러 테이핑 방법들 이 개발되어 사용되고 있다. ${ }^{6}$

골격근의 기능을 증진시키는 또 다른 방법으로는 수의적 수축을 이용하는 방법과 전기 자극에 의한 수축을 이용하는 방 법이 있으며, 전기 자극에 의한 근 수축이 수의적 등척성 운동 에 의한 근 수축과 유사하게 근력 향상을 가져온다고 하였 다 ${ }^{7,8)}$ 근 기능을 향상시키기 위한 전기 자극 중 신경근 전기 자극(Neuromuscular electrical stimulation)은 정상 성인에 게 적용했을 때 근력을 높이는데 효과적이라 하였다." Lake $^{9}$ 
$(1992)^{10)}$ 에 의하면 신경근 전기자극에 사용되는 전류는 쌍점 단상성 펄스전류(twin-spiked monophasic pulsed current), 돌발 변조교류(burst-modulated alternative current : 러시 안 전류), 이상성 펄스전류(biphasic pulsed current) 등이 있다고 하였다. Barbeau 등 $(1998)^{11)}$ 은 신경근 전기자극이 근력 강화, 지구력 강화, 관절운동범위의 증가, 혈류량 증진, 운동조절 능력 촉진, 고정으로 인한 근 위축 및 약화방지와 개 선 등 다양한 목적에 사용된다고 하였다. 신경근 전기 자극에 주로 사용된 전류는 러시안 전류(Russian current)였으며, $50 \%$ 의 순환주기(duty cycle)와 $50 \mathrm{~Hz}$ 돌발변조 주파수(burst modulation frequency)를 발생시킬 수 있는 $2,500 \mathrm{~Hz}$ 교류 이다. ${ }^{12)}$

Felder(1994) ${ }^{13)}$ 에 의하면 전기자극과 수의적 근 수축을 병행하면 주로 힘(power)과 근력(strength)이 증가한다고 하 였다. 지속적으로 근 섬유의 활성이 발생하면 근피로 현상이 나타나게 된다. ${ }^{14)}$ 근육의 피로는 근육의 반복적인 활동으로 인 해 요구되거나 기대되는 힘을 유지할 수 없는 것으로 장시간 또는 과도한 활동으로 야기되는 불쾌, 능률 저하 그리고 자극 에 대한 반응 능력의 상실을 의미한다. ${ }^{15)}$ Bigland-Ritchie와 $\operatorname{Wood}(1984)^{16)}$ 는 근 지구력과 근피로는 상반된 개념이며, 근 피로는 근력 발생능력이 감소하는 것을 의미한다고 하였다.

신경근전기자극과 수의적 근수축을 병행하면 근력이 증가 한다는 많은 연구자들의 연구가 있었으나 ${ }^{3),}{ }^{17)}$ 이러한 연구 발 표에도 불구하고 신경근 전기자극과 수의적 근 수축을 병행하 였을 때 근 피로에 관한 연구는 아직까지 부족한 실정이다. 이 에 본 연구는 병원이나 가정에서 널리 사용되고 있는 키네시오 테이핑과, 러시안 전류자극을 적용 한 스쿼트 운동이 넙다리네 갈래근의 피로도에 어떠한 영향을 미치는지 알아보고 비교하여 임상적 효율성을 평가하는데 필요한 자료로 활용하고자 실시하 였다.

\section{II. 연구 방법}

\section{1. 연구대상}

본 연구는 부산에 소재하는 C대학의 20 대 건강한 성인 60 명 (남성 18명, 여성 42 명)을 대상으로 하였다. 연구대상자는 연구 자의 지시를 따르는데 문제가 없으며, 연구의 운동을 진행하기 에 충분한 근력을 가지고 있으며, 최근 6 개월간 정형외과적 문 제가 있었던 자는 제외하였다. 또한, 연구대상자들은 실험 전에 연구의 목적과 과정 그리고 연구의 의의에 대해 설명을 들었으 며 자발적으로 연구에 동의하였다. 연구대상자들의 인구학적 정 보에서 집단 간 유의한 차이는 나타나지 않았다(Table 1).
Table 1. General characteristics of the subjects

\begin{tabular}{lccc} 
Variables & $\begin{array}{c}\text { KG } \\
(\mathrm{n}=20)\end{array}$ & $\begin{array}{c}\mathrm{R} \text { (n=20) } \\
(\mathrm{n}=20\end{array}$ & \multicolumn{1}{c}{$\begin{array}{c}\mathrm{CG} \\
(\mathrm{n}=20)\end{array}$} \\
age $(\mathrm{yrs})$ & $22.6 \pm 0.9$ & $22.1 \pm 1.3$ & $21.4 \pm 1.6$ \\
height $(\mathrm{cm})$ & $163.5 \pm 9.9$ & $165.5 \pm 7.9$ & $164.9 \pm 7.5$ \\
weight $(\mathrm{kg})$ & $57.3 \pm 12.3$ & $61.3 \pm 11.0$ & $59.5 \pm 6.5$ \\
\hline
\end{tabular}

\section{2. 연구 절차}

연구대상자들은 키네시오 테이핑군(kinesio taping group $(\mathrm{KG})$ ), 러시안전류군(Russian current $\operatorname{group}(\mathrm{RG})$ ), 대조군 (control group(CG))으로 각각 20명씩 무작위로 배치하였다. 넙다리네갈래근에 피로를 유발하기 위해 연구대상자는 두 발을 어깨너비로 벌리고 양발을 각각 $60^{\circ}$ 로 벌리고 유지한 선 자세 에서 양팔은 가볍게 팔짱을 끼고 체간은 기립을 유지한 자세로 스쿼트 100 회를 시행하였다. ${ }^{18)}$ 연구대상자들은 운동 수행 전, 키네지오테이핑과 러시안 전류를 각각 적용한 후 운동을 실시 하였으며 대조군은 아무런 처치없이 스쿼트 운동을 시행하였 다. 그리고 근 피로도 측정을 위해 운동 전과 후에 각각 근전 도 신호를 통해 중앙주파수를 구하였다.

\section{3. 연구방법}

(1) 키네시오 테이핑군(KG)

키네시오 테이핑군은 테이핑을 안쪽넓은근(vastus medialis, $\mathrm{VM})$, 가쪽넓은근(vastus lateralis, $\mathrm{VL}$ ), 넙다리곧은근(rectus femoris, RF)에 대해 적용한 후 스쿼트 운동을 100 회 시행하 였으며 키네시오 테이핑은 넙다리네갈래근에 적용하는 전통적 인 Y형 테이핑 방법을 사용하였다.19-20)(Figure 1).

\section{Figure 1 The attachment method of kinesio taping}




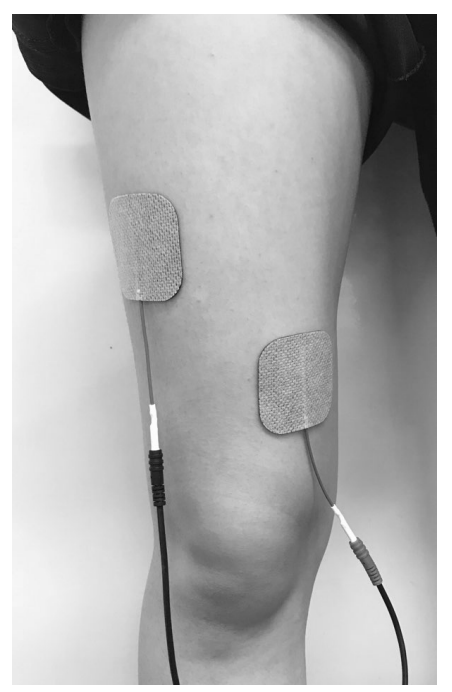

Figure 2 The attachment method of Russian current

(2) 러시안 전류군(RG)

러시안 전류군은 2 개의 전극을 배치하였다. 하나의 전극은 가 쪽넓은근 $(\mathrm{VL})$ 의 먼 쪽 부분에, 다른 하나는 안쪽넓은근 $(\mathrm{VM})$ 의 먼 쪽 부분에 부착하여 스쿼트 운동을 100 회 시행하였다 (Figure 2). 전류는 $20 \mathrm{~mA}$ 에서 $25 \mathrm{~mA}$ 사이에서 조절하여 근수 축이 가장 잘 일어나는 강도로 자극하였고 단속 시간비(on-off ratio)는 1:2 즉, 10 초 자극 후 20 초 동안 휴식하도록 하였으 며 맥동기간(pulse width)은 $250 \mu \mathrm{s}$, 맥동빈도(pulse rate)는 50pps로 설정하였다 ${ }^{3}$.

(3) 대조군(CG)

대조군은 위의 조건에서 아무 조치를 하지 않고 스쿼트 운동을 100 회 시행하였다.

(4) 근전도 측정 및 분석 방법

근피로도 측정을 위해 근전도는 WEMG8(Laxtha, Korea)을 사용하였으며, 근전도 측정은 스쿼트 운동 수행 전·후에 실시하 였다. 이후 원 데이터(raw data)를 분석하기 위해 telescan 프로그램(telescan, Laxtha, Korea)을 이용하였다. 샘플링 주 파수는 $1024 \mathrm{~Hz}$ 로 하였고, 이는 값을 제곱한 뒤 적분하여 제곱 근 한 RMS 값으로 계산되었으며 전자기기의 잡음을 제거하기
위해 10-500 Hz로 대역통과필터(band-pass filtering)를 실시 하였다. 근전도 신호는 연구대상자의 정확한 최대 강도의 힘을 측정하기 위해 측정 된 30 초 중 앞. 뒤 5 초씩을 제외한 20 초의 데이터를 RMS 값으로 처리하여 사용하였다. 전극 중심 간 거 리는 $2 \mathrm{~cm}$ 로 하였으며 전극 부착 부위는 측정오류의 방지를 위 해 면도 후 의료용 알코올로 깨끗이 닦은 후 안쪽넓은근(VM), 가쪽넓은근 $(\mathrm{VL})$, 넙다리네갈래근(RF)에 부착하였다. 안쪽넓은 근(VM)의 전극은 무릎뼈 안쪽면 위 $2 \mathrm{~cm}$ 에 부착하였으며, 가 쪽넓은근 $(\mathrm{VL})$ 의 전극은 넙다리뼈의 중앙선을 기준으로 무릎빼 가쪽 위 $3-5 \mathrm{~cm}$ 에 부착하였고, 넙다리네갈래근(RF)의 전극은 무릎과 위앞엉덩뼈가시의 중간에 부착하였다. ${ }^{21)}$

\section{4. 통계 방법}

통계 처리는 각 군별 중재 전·후 비교를 위해 paired t test를, 그룹 간 비교를 위해 전후의 근피로도 차이값을 구한 다음 one-way ANOVA를 이용하여 분석하였다. 통계적 유의성을 검정하기 위하여 유의수준(a)은 0.05 로 하였다.

\section{III. 결 과}

본 연구는 넙다리네갈래근에 적용한 테이핑과 러시안 전류자극 이 고강도 운동시 근피로도에 미치는 영향을 알아보기 위하여 실시하였다. 스쿼트 전·후 넙다리네갈래근의 근피로도에 대한 $\mathrm{EMG}$ 측정 결과는 다음과 같다.

\section{1. 키네시오 테이핑군에서 스쿼트 운동 전·후 근피로도의 차이} 키네시오 테이핑 $(\mathrm{KG})$ 을 적용하여 운동 전·후 중앙주파수 변화 를 측정한 결과 가쪽넓은근과 넙다리곧은근에서는 운동전과 후 에 유의한 차이가 나타나지 않았으며, 안쪽넓은근(vastus medialis, VM)은 운동 전과 후에 유의한 차이가 있었다 $(\mathrm{p}<0.05)($ Table 2$)$.

\section{2. 러시안 전류자극 군에서 스쿼트 운동 전·후 근피로도의 차이} 러시안 전류자극 $(\mathrm{RG})$ 를 운동 전·후 중앙주파수 변화를 측정한 결과 가쪽넓은근, 안쪽넓은근, 넙다리곧은 모두에서 유의한 차 이가 없었다 $(\mathrm{p}>0.05)$ (Table 3$).$

Table 2. The comparison of VL, RF, VM for pre-training and post-training in kinesio taping group

\begin{tabular}{cccccc}
\hline kinesio taping group & Pre & Post & $\mathrm{t}$ & $\mathrm{p}$ \\
vastus lateralis & $50.42 \pm 10.54$ & $51.17 \pm 8.59$ & -.237 & .815 \\
rectus femoris & $59.81 \pm 16.96$ & $59.06 \pm 15.74$ & .292 & .773 \\
vastus medialis & $46.71 \pm 8.48$ & $50.65 \pm 9.48$ & -2.288 & .034 \\
\hline
\end{tabular}


Table 3. The comparison of VL, RF, VM for pre-training and post-training in Russian current group

\begin{tabular}{|c|c|c|c|c|}
\hline kinesio taping group & Pre & Post & $\mathrm{t}$ & p \\
\hline vastus lateralis & $56.77 \pm 15.02$ & $57.13 \pm 13.78$ & -.206 & .839 \\
\hline rectus femoris & $52.66 \pm 13.30$ & $53.98 \pm 14.58$ & -.450 & .658 \\
\hline vastus medialis & $48.17 \pm 6.71$ & $47.95 \pm 7.93$ & .145 & .886 \\
\hline
\end{tabular}

Table 4. The comparison of VL, RF, VM for pre-training and post-training in Control group

\begin{tabular}{cccccc}
\hline kinesio taping group & Pre & Post & $\mathrm{t}$ & $\mathrm{p}$ \\
vastus lateralis & $52.88 \pm 9.31$ & $50.76 \pm 10.46$ & .699 & .492 \\
rectus femoris & $64.15 \pm 21.94$ & $66.26 \pm 22.74$ & -.704 & .489 \\
vastus medialis & $48.83 \pm 9.34$ & $48.28 \pm 8.27$ & .437 & .666 \\
\hline
\end{tabular}

Table 5. The comparison of pre-post differences among the three groups

\begin{tabular}{ccccccc} 
& & kinesio taping group & Russian current group & control group & $F$ & $p$ \\
vastus lateralis & 0.75 & 0.36 & -1.25 & 0.17 & 0.84 \\
rectus femoris & -0.75 & 1.32 & 2.87 & 0.36 & 0.69 \\
vastus medialis & 3.93 & -0.22 & -0.50 & 2.46 & 0.09 \\
\hline
\end{tabular}

\section{3. 대조군(CG)에서 스쿼트 운동 전·후 근피로도의 차이} 대조군의 운동 전과 후의 중앙주파수 값은 가쪽넓은근, 안쪽넓 은근, 넙다리곧은 모두에서 유의한 차이가 없었다 $(\mathrm{p}>0.05)$ (Table 4).

\section{4. 그룹 간 운동 전과 후 차이값 비교}

그룹간 비교를 위해 키네시오 테이핑군, 러시안 전류군, 대조군의 운동 후에서 운동 전 값을 뺀 중앙주파수 차이값은 다음과 같으 며 모두 유의한 차이가 나타나지 않았다 $(\mathrm{p}>0.05)$ (Table 5).

\section{IV. 고 찰}

본 연구는 키네시오 테이핑과 러시안 전류자극을 적용한 고강 도운동 시 근피로에 미치는 영향을 알아보고자 스쿼트 운동을 실시하고 운동 전과 후의 넙다리네갈래근의 피로도의 변화를 측정하였다.

근피로도를 분석하는 여러 방법 중 근전도법은 표면 근전 도를 이용한 근피로의 분석으로 근전도 신호의 진폭을 반영한 실효치 진폭과 주파수 스펙트럼 분석에 의한 중앙주파수 (median power frequency), 평균 주파수(mean power frequency) 등을 피로 지수로 이용한다. ${ }^{22-24)}$ 근피로 발현 시, 저주파에서의 전력 증가 그리고 고주파에서의 전력 감소 또는 저주파에 대한 고주파 비율의 감소로 인해 근육에서의 중앙 주 파수(MF)가 낮은 주파수대로 이동하게 된다. ${ }^{25-27)}$
Binder-Macleod 등(1993) ${ }^{28)}$ 은 수의적인 근 피로와 전기 자극에 의한 근피로의 양을 측정하고 이를 정량화하기 위해 신 경근전기자극을 사용하여 지속적인 힘으로 출력되는 자극으로 반복수축 시 발생하는 피로도를 측정하였다. 그 결과 전기 자 극에 의한 수축력과 주파수는 피로에 직접적으로 영향을 주는 데, 주파수가 높을수록 근 피로를 더욱 유발할 수 있다고 보고 하였다. 본 연구에서도 고강도 운동을 실시하는 동안 중주파인 러시안전류를 적용한 결과, 통계적으로 유의한 차이는 없었으 나 모든 근육에서 중앙중파수값이 높게 나타났다. 아무런 처치 없이 운동을 실시한 대조군에서 운동 후 중앙중파수 값이 대체 로 낮게 나타난 것과 비교할 때, 러시안전류의 자극이 근 피로 에 영향을 주었을 것이라 볼 수 있을 것이다. 러시안 전류를 활용해 근피로도를 살펴본 최근의 연구에서 정성관 등 $(2010)^{17)}$ 은 건강한 성인 14 명을 대상으로 넙다리네갈래근에 최대 수의적인 등척성 수축운동 시 러시안 전류를 적용한 결 과, 유의하지는 않았으나 근피로가 적게 발생한다고 하여 본 연구의 결과를 뒷받침하는 연구라 생각된다.

키네시오 테이핑은 테이프를 신장시켜 피부에 붙이면 피부 아래 공간이 확장 된다. 이로 인해 림프액 및 혈액 순환을 촉 진시켜 염증 및 통증 감소, 관절가동범위 등의 회복, 근력 및 근지구력을 향상시키기 위한 목적으로 사용되고 있다. ${ }^{29)}$ 또 테 이핑으로 인해 말초에 가해진 구심성 자극이 운동 겉질의 흥분 성을 증가시키고 피부 자극으로 운동 신경원의 역치가 감소되 어 운동 단위의 동원이 쉬워지면 자극 부위 아래 근육의 수축 을 촉진시킬 수 있다고 하였다. ${ }^{20)}$ 
김수현 등 $(2016)^{14)}$ 의 연구에서는 20 대 건강한 성인 남자 30 명을 대상으로 넙다리네갈래근에 키네시오 테이핑을 적용한 후 스쿼트 운동과 트레드밀 운동을 실시하였을 때 근 활성도가 유의하게 증가하였고 근피로도는 유의하게 발생하지 않았다고 하였다. 하지만 박기범(2005) $)^{30}$ 은 정상성인 14 명을 대상으로 하지에 키네시오 테이핑을 적용하여 등속성 근 기능을 측정하 였으며 테이핑을 적용한 그룹에서 운동 후 주파수 감소율이 유 의하게 높게 나타났다고 하였다. 서병도 $(2011)^{31)}$ 의 연구에서 도 건강한 젊은 남성 15 명을 대상으로 넙다리네갈래근에 키네 시오 테이핑을 적용한 후 윈게이트 검사를 통해 근파워와 근피 로를 측정하였을 때 근피로가 유의하게 발생한다고 하였다. 본 연구에서는 키네시오 테이핑을 적용한 후 스쿼트 운동 시 넙다 리곧은근에서는 중앙주파수 값이 감소하고 가쪽넓은근에서는 중앙주파수 값이 증가하였으나 그 변화의 차이가 매우 적고 유 의한 차이가 없었다. 그에 비해 안쪽넓은근에서는 중앙주파수 값이 유의하게 증가하였다. 이는 키네시오 테이핑의 적용으로 말초에 가해진 구심성 자극이 운동 겉질의 흥분성을 증가시켜 운동 단위가 쉽게 동원 되어 근육의 수축이 촉진되었기 때문이 라고 생각된다. 이성도(2010) ${ }^{32)}$ 의 연구에서 1 년 이상 웨이트 트레이닝 운동 경력이 있는 숙련자 3명, 웨이트 트레이닝 운동 경력이 전혀 없는 초보자 3 명을 대상으로 스쿼트 운동 시 운동 부하 증가에 따른 근 활성도와 자세변화를 보았을 때 부하의 증가에 따라 가쪽넓은근과 안쪽넓은근의 근 활성도가 가장 높 게 나타났다고 하였다. 본 연구에서 키네시오 테이핑 적용 후 가쪽넓은근과 특히 안쪽넓은근의 근피로도가 유의하게 감소한 것으로 나타나 테이핑의 적용이 근 피로에 영향을 미친 것을 알 수 있었다.

이상의 결과를 통해 키네시오 테이핑 적용이 스쿼트 운동 시 안쪽넓은근의 근피로 감소에 유의한 영향을 미쳤음을 알 수 있었다. 하지만 본 연구는 첫째, 실험결과를 일반화하여 해석하 기에 대상자의 수가 부족하였으며 둘째, 스쿼트 자세에 영향을 줄 수 있는 무릎 정렬 상태를 특별히 제한하지 않았다는 제한 점이 있다.

\section{V. 결 론}

본 연구에서는 고강도 운동시 러시안 전류자극과 키네시오 테 이핑이 근 피로에 미치는 영향을 알아보기 위해 스쿼트 운동을 100 회 실시한 후 근 피로도를 비교하였다. 그 결과, 키네시오 테이핑을 적용한 후 운동을 했을 때 안쪽넓은근에서 유의한 근 피로의 감소가 있었다. 따라서 고강도 운동시 키네시오 테이핑 을 적용 한 후 운동을 실시하면 효율적으로 근력과 근지구력을 강화시킬 수 있을 것이라 생각한다.

\section{References}

1. Jung EN, Yook DW, Park YS, et al. Psychological changes in Elite Athletes during Sport Injury Rehabilitation. Korean Journal of Sport Science. 2005;26(4):723-38.

2. Kim BJ. (The) effect of massage on total work during high intensity intermittent isokinetic exercise on taekwondo players' Knee. Dissertation of Master's Degree of Kyounggi University. 2005.

3. Go TS. Effects of russian current stimulation or progressive resistive exercise on muscle strength and endurance change. Dissertation of Master's Degree of Yongin University. 2000.

4. Zhang S, Fu W, Pan J, et al. Acute effects of Kinesio taping on muscle strength and fatigue in the forearm of tennis players. J Sci Med Sport. 2016;19(6):459-64.

5. Zanca GG, Gruninger B, Mattiello SM. Effects of Kinesio taping on scapular kinematics of overhead athletes following muscle fatigue. J Electromyogr Kinesiol. 2016;29:113-20

6. Host HH. Scapular taping in the treatment of anterior shoulder impingement. Phys Ther. 1995;75(9):803-12.

7. Lieber RI, Silva PD, Daniel DM. Equal effectiveness of electrical and volitional strength training for quardriceps femoris muscles after ACL surgery. J Orthop Res. 1996;14(1):131-8.

8. Maffiuletti NA, Cornetti G, Amiridis IG. The effects of electromyostimulation training and basketball practice on muscle strength and jumping ability. Int $\mathrm{J}$ sports Med. 2000;21(6):437-43.

9. Cabric M, Appell HJ, Resic A. Fine structural changes in electrostimulated human skeletal muscle. Evidence for predominant effects on fast muscle fibres. Eur J Appl Physiol Occup Physiol. 1988;57(1):1-5.

10. Lake DA. Neuromuscular electrical stimulation. An overview and its application in the treatment of sports injuries. Sports Med. 1992;13(5):320-36.

11. Barbeau $H$, Norman $K$, Fung $J$, et al. Does neurorehabilitation play a role in the recovery of walking in neurological populations. Ann N Y Acad Sci, 1998;86:377-92.

12. Selkowitx DM. Improvement in isometric strength of the quadriceps femoris muscle after training with electrical stimulation. Phys Ther. 1985;70:416-22.

13. Felder $\mathrm{H}$. The effect of electromyostimulation on selected power parameters, Germany, Sportverletzung Sportschaden. 
1994;8(3):122-7.

14. Kim SH, Kim HJ. The Effects of a Kinesio Taping on Muscle Activity and Muscle Fatigue in Quadriceps Femoris. Journal of Sport and Leisure Studies. 2016;63:663-71.

15. Edwards RH. Human muscle function and fatigue. Ciba Found Symp. 1981;82:1-18.

16. Bigland-ritchie B, Woods JJ. Changes in muscle contractile properties and neural control during muscular fatigue. Muscle\& Nerve 1984;7:691-9.

17. Jung SG, LEE WH, Kim JS. Effects of the Application of Russian Current on Quadriceps Femoris Muscle Torques and Fatigue. Journal of The Korean Data Analysis Society. 2010;12(5):2467-78.

18. Kim HH, Song CH. Effects of Knee and Foot Position on EMG Activity and Ratio of the Vastus Medialis Oblique and Vastus Lateralis during Squat Exercise. The Journal of Muscle and Joint Health. 2010;17(2):142-50.

19. Lins $\mathrm{CA}$, Neto FL, Amorim AB, et al. Kinesio Taping((R)) does not alter neuromuscular performance of femoral quadriceps or lower limb function in healthy subjects: randomized, blind, controlled, clinical trial. Man Ther. 2013;18(1):41-5.

20. Wong OM, Cheung RT, Li RC. Isokinetic knee function in healthy subjects with and without Kinesio taping. Phys Ther Sport. 2012;13(4):255-8.

21. Cram JF, Kasman G. introduction to surface EMG. Gaithersburg, MD: Aspen; 1998

22. Allahyari T, Mortazavi N, Khalkhali HR, et al. Shoulder girdle muscle activity and fatigue in traditional and improved design carpet weaving workstations. Int J Occup Med Environ Health. 2016;29(2):345-54.

23. Basmajian JV, Deluca CJ. Description and analysis of the EMG signal; Muscle Alive(5th Ed.). USA, William\&Wilkins, 1985:26-57.

24. Vollestad NK. "Measure of humanmuscle fatigue". J Neurosci Methods". 1997;74:219-27.

25. Gerdle B, Larsson B, Karlsson S. Criterion validation of surface EMG variables as fatigue indicators using peak torque:A study of repetitive maximum isokinetic knee extensions. J Electromyogr Kinesiol. 2000;10(4):225-32.

26. Kumar S, Mital A. Electromyography in ergonomics. Boca Raton (FL): CRC Press; 1996.

27. Blangsted AK, Sjøgaard G, Madeleine P, et al. Voluntary low-force contraction elicits prolonged low-frequency fatigue and changes in surface electromyography and mechanomyography. J Electromyogr Kinesiol. 2005; 15(2):138-48.

28. Binder-maclod SA, Snyder-mackler L. Muscle fatigue: clinical implications for fatigue assessment and neuromuscular electrical stimulation. Phys Ther. 1993;73(12):902-10.

29. Kase K, Wallis J, Kase T. Clinical therapeutic applications of the Kinesio Taping method 3rd Edition, USA, Kinesio USA, LLC, 2013.

30. Park GB, Lee WJ, Han SW. The Effects of Kinesio taping therapy on exercise capacity and muscle fatigue. The Korea Journal of Sports Science. 2009;18(2):1101-15.

31. Seo BD, Jung NJ, Park SW, et al. The Effect of a Kinesio taping on muscle power and fatigue index in quadriceps femoris. Journal of Korean academy of orthopaedic manual therapy. 2011;17(1):29-34.

32. Lee SD. Effect of weighs on lower extremity muscular activity during squat exercise. Dissertation of Master's Degree of Kookmin University. 2010. 